\title{
Evaluating the ENQA's Benchmarking Practice: Possible Strategies for the New Comers
}

\author{
Denisa Krbec \\ Faculty of Economics and Tourism Pula \\ University of Rijeka, Croatia
}

dkrbec@efpu.hr

\begin{abstract}
The origins of the concept of benchmarking show us the reason for its popularity primarily under the pressures of rapid internationalization in a wider context. The international competitiveness, the 'movement' for qualities, and the rapid growth of information technology, which has made sophisticated data collection possible, were usually identified as main economic and social impacts on the practice's implementation.

Even the main key activities of the European Network for Quality Assurance in Higher Education (ENQA) are training and advisory support, this paper aim is to analyze the network's other tasks such as dissemination of general information, experiences, and good practices.

How is it possible to transfer the best practices and techniques across institutions and across cultures efficiently and rapidly? Evaluation for accreditation purposes has been used in some Eastern European countries, such as Croatia, to determine the minimum level of degree programs. This paper summarizes policy recommendations made by European evaluation experts.
\end{abstract}

Keywords: Benchmarking, Quality, Organizational Behavior, Higher Education, Croatia.

\section{Introduction}

For all national higher education systems currently participated in the European University Association (EUA), the European Network for Quality Assurance in Higher Education (ENQA) serves as an agency for promotion of European co-operation in the field of quality assurance in higher education. According to the regulations amended by the Board November 2005, the ENQA's objectives should encourage and develop different evaluation, co-operation, and quality assurance processes in order to establish the European Higher Education Area (EHEA). Quality assurance agencies of the Bologna process signatory states are invited to participate in this process.

As a membership organization with the mission to promote cooperation, exchange best practices and stimulate the professional development, ENQA has also a political role as the advocate of the

Material published as part of this publication, either on-line or in print, is copyrighted by the Informing Science Institute. Permission to make digital or paper copy of part or all of these works for personal or classroom use is granted without fee provided that the copies are not made or distributed for profit or commercial advantage AND that copies 1) bear this notice in full and 2) give the full citation on the first page. It is permissible to abstract these works so long as credit is given. To copy in all other cases or to republish or to post on a server or to redistribute to lists requires specific permission and payment of a fee. Contact Publisher@InformingScience.org to request redistribution permission. quality assurance community in the power game with national governments, institutions and their organizations and the European Commission.

As Croatia continues efforts to integrate with the European Union, it faces the necessity of adaptation its education system to standards imposed by the European University Association. Since the sociologists analyses these activities of performance as deeply embedded in 
functioning of the "evaluative" state, there are existing also analyses of different pressures on the higher education administrators to effectively respond to the performance-based state agendas for public institutions.

The first evaluation procedure in Croatian higher education according to the Bologna process's requirements (held in 2005) predicted both national and international assessment and included a number of institutions and individuals, of whom all are engaged in enhancing the quality of higher education. The mixture of internal and external benchmarking was supported by European experts as well as it's stressed out like a need to optimize the impact of structural change on curricula in order to introduce the innovative teaching and learning processes.

\section{The Models of Organizational Behavior}

Universities are complex systems with diversified interests that usually do not lend themselves to the rational modeling found in the contemporary sociology. Furthermore, given collegial traditions favoring shared governance and consensus, it has been difficult to establish the (individual) preferences to modeling the internal as well as the external processes of the quality assessment.

Recent educational theoretical approaches as well as specific (higher) education researches use different, sometimes quite opposite, models and methods in order to examine parts of education reform as a function of a systemic process. The main model of organizational behavior that leads to understand the dynamics complex systems is the multidimensional dynamic model (MDM) usually used with one of the dimensions:

- bureaucratic,

- collegium, or

- symbolic dimension.

As Pusser (2003) pointed out, the multidimensional dynamic model of organizational behavior is one of the fundamental analytical frameworks in higher education research. The model varies somewhat in the number of dimensions incorporated, ranging from Baldridge's original three dimensions (bureaucratic, collegial, and political) through Bolman and Deal's four-cornered frame (structural, human resource, political, and symbolic) to Birnbaum's five dimensions (bureaucratic, collegial, political, anarchical, and cybernetic). What these models have in common is that each of these iterations has incorporated the political dimension developed by Baldridge, known as the Baldridge criteria.

The bureaucratic dimension is essentially the rational, goal-driven model developed in the work of Max Weber. The central elements of the Weberian bureaucratic frame are an efficient organizational process; formal, hierarchical administrative structures; well-delineated institutional rules; and a similarly well-defined division of labor. The bureaucratic frame relies on a clear distinction between personal and institutional property rights, the centrality of credentials and expertise in determining institutional hierarchies, and a focus on merit as a source of organizational legitimacy. Organizational decision making is characterized as a process of top-down, rational deliberation that leads to stability and legitimate administrative control.

Within the collegial dimension, organizations are viewed as entities based on collective action and widely shared values. Decision-making is seen as a participatory, pluralist, and democratic process within a collegium or community of scholars (Bush, 1995). Goals are shaped by collective action and guided by consensus; power and decision-making are shared throughout the organization. Following principles of the collegial frame's establishment, conflict is a form of collegial dysfunction. It's easy to find a solution that the Baldridge criteria found when incorporated 
a number of elements of the collegial dimension in his depiction of interest articulation in higher education.

The third dimension, guided by the symbolic interactionists' perspective, the symbolic dimension stresses informal authority, with shared networks of norms, beliefs, meanings, and cultural understandings key to shaping organizational structures and processes (Meyer \& Rowan, 1977). According to their famous elaboration on myths and ceremonies, organizational decisions emerge in response to social and cultural demands for conformity to prevailing values and sources of legitimacy, as under conditions of considerable uncertainty, organizational actors rely on symbolic action to increase institutional confidence and stability. Believes are legitimate organizational behavior that binds the institution, and rational decisions are given down through a hierarchical structure.

Universities are developing a unique model of organizational culture progressing from a collegium/bureaucratic organizational framework to an enterprise/corporate model. The activities of performance are deeply embedded in the evaluative state, such Eastern European countries currently are. Like the higher education administrators worldwide have been pressured to respond to the performance-based state agendas for public institutions, European universities cannot be isolated from the environment in which they operate.

A performance model includes also different social indicators which are, combined with broader ideological or political mechanisms, variously characterized as a public sector reform, new public management (in Anglo-Saxon systems) or new governance reform (other countries in the European Union). The foundation of structural changes extends beyond any ideological reform or political impact on public-sector institutions:

Although Europe has come up with various national evaluation solutions, there are some common features: all encompass self-evaluation conducted by the higher education institutions themselves, as well as a visit of an external review team who utilise self-evaluation documents and interviews, and a final report (Hämäläinen, Pehu-Voima, \& Valhén, 2001, p.6).

In the well known models of performance currently held in European academic and research areas, accountability and service improvement are usually taken as common goals. Among traditionally different organized education systems, and specifically targeted ones on various levels of the internal organization and management of it, several (listed bellow) are often represented as common to all:

- stimulation of internal and external institutions' competition;

- verification of the quality of new or re-formed institutions;

- assignation of institutional status (university/non-university, academic/non-academic etc.);

- justification's transfer from the state authority to an institutional level (or: the authority's decentralization), and

- facilitation of international comparisons and quality assessment.

Brennan concluded that the particular combination of goals depends on specific national contexts and the balance within them of accountability, markets, and trust (Brennan, 1999). On the basis of the analyses taken in 1990's, Brennan reports that while impacts are conditioned by the nature of the individual institution and the distribution of authority in the HE system, performance mechanisms appear to have raised the profile of teaching and learning in HE institutions. He found that overall impact is increased when the mechanisms gain the legitimacy at the faculty level, and that increased centralization and managerialism is characteristic at the institutional level. 


\section{The Contexts of Institutional Evaluation}

Various subjects in higher education, starting from the governments, national associations/ committees, universities and universities' associations (including the Rectors' conferences and academic leaders workshops), and institutional leaders in particular are all, in a ways, interested in obtaining data for international comparative analyses into the scale of resources made available to universities and the efficiency of the latter in fulfilling their basic commitments.

The European University Association (EUA) established more constructive approach's comparisons at international level using the benchmarking as a technical tool to ensure that findings can be meaningfully compared. These EUA's approach, followed by the General Report 2003-2005 from the Follow-up Group and The Council of Europe - the National Unions of Students in Europe's (ESIB) report "Bologna with Students Eyes", focused on quality assurance as the systematic introduction of internal mechanisms and their direct correlation to external quality assurance ("The European higher education area," 2005).

Any statistical indicator used for comparative purposes should thus be selected only after a detailed assessment of the present situation in the institutions concerned has been performed and in such a way as to ensure they are as representative as possible.

\section{Dimensions of Benchmarking}

At the Conference of European Ministers Responsible for Higher Education held in Bergen, 1920 May 2005, the ENQA's standards and guidelines for quality assurance (based on the proposal from the Expert Group's Workshop from 2002) were again confirmed. (The European Commission supported the establishment of the European Network for Quality Assurance in Higher Education (further: ENQA), which became operational in 2000. ENQA is a membership organization with the mission to promote cooperation, exchange best practices and stimulate the professional development of its members and their personnel. But, it undoubtedly also has a political role as the advocate of the quality assurance community in the power game with national governments, institutions and their organizations and the European Commission. Today, ENQA has 36 members from 21 European countries.)

The confirmation underlined the importance of cooperation between "nationally recognized agencies with a view to enchasing the mutual recognition of accreditation or quality assurance decisions" ("The European higher education area," 2005).

The ENQA's standards are based on three related dimensions of benchmarking in higher education:

1. national or international;

2. internal or external, and

3. benchmarking concentrated either on the process itself or on the output, or both.

National benchmarking in its "pure" form includes e.g. the establishment of subject benchmarks for programs offered within the context of the higher education (present accreditation procedures in Croatian higher education). There is also the social dimension included in the national benchmarking standards mostly accessible trough different government's measures for helping students, especially from socially disadvantaged groups (guidance, counseling etc.). In the Bergen Communiqué Ministers pointed out - among others - implementation of the national frameworks for qualification as one of the priorities for the next Ministerial Conference in 2007 ("The European higher education area," 2005). This priority is directly correlated to the necessity of upholding the principle of public responsibility for $\mathrm{HE}$ in the context of complex modern societies.

The distinction between external and internal benchmarking involves at least two dimensions: 
a) where the initiative was taken by and agency external to those being evaluated, and

b) the extent to which the project involves external partners.

The internal elements like self-evaluation or self-assessment, however, are not included in the evaluation process of external partners. It's of an importance to highlight that four categories have been identified by Alstete (1995). The categories are based upon the voluntary and proactive participation of institutions. They represent an extended strategic approach to the basic distinctive classification between internal and external type of benchmarking. Alstete observes that "benchmarking can help overcome resistance to change that can be very strong in conservative organizations, such as colleges and universities, that have had little operational change in many years" (Alstete, 1995, p.25). An internal-external relation can be extended to subsequent types:

1. Internal benchmarking in which comparisons are made of the performance of different departments, campuses or sites within a university in order to identify best practice in the institution, without necessarily having an external standard against which to compare the results. This type may be particularly appropriate to universities where a high degree of devolvement exists to the constituent parts of the institution, where a multi-campus environment exists, or where extensive franchise arrangements exist whereby standard programs are taught by a number of partner colleges in different locations.

2. External competitive benchmarking where a comparison of performance in key areas is based upon information from institutions that are seen as competitors. Although initiatives of this kind may be potentially very valuable, and have a high level of 'face' validity amongst decision makers, the process may be fraught with difficulty and is usually mediated by neutral facilitators in order to ensure that confidentiality of data is maintained.

3. External collaborative benchmarking usually involves comparisons with a larger group of institutions who are not immediate competitors. Several such initiatives are reported below, and the methodology is usually relatively open and collaborative. Such schemes may be run by the institutions themselves on a collective basis, although in other cases a central agency or consultant may administer the scheme in order to ensure continuity and sufficient momentum.

Based on American experiences, Bass and Avolio (1994) suggested the organizational effectiveness improvement's making through a transformational leadership in a way to change the organization's operational culture as well. Successful transformational leaders, through motivating others, are frequently able to accomplish more than they had intended; it's up to the leaders to ensure that the university is working effectively to achieve its strategic goals, meet its accreditation standards, and realize its mission (see: Bender, 2002, pp. 115, 119).

\section{European Practices}

The European practices yet applied on higher education institutions usually involve both examples, internal and external. The mixture of internal and external benchmarking is supported from European experts as well as it's stressed out like a need to optimize the impact of structural change on curricula in order to introduce the innovative teaching and learning processes (Tavenas, 2004).

All cases presented at the ENQA's workshop in 2002 included a process-oriented approach to evaluation and benchmarking. Supported by the meaning of benchmarking as a long-term process that is not static, these applications are to support and internal process for continuous quality improvement.

Currie, Krbec and Higgins (2005) elaborated the main principles of a continuous quality improvement based on the process-oriented approach. When quality management permeates an or- 
ganization, the strategic objectives established by senior managers will be translated into directions for all levels of the organization, and each level will develop processes to help it achieve subsidiary objectives that are tied to the overall objectives of the organization.

Inherent in the quality management process is that individuals responsible for an outcome should have the authority to take actions that influence changes in that outcome. This linking of responsibility with authority is called empowerment, and it encourages employees to be innovative and responsive in addressing the organization's objectives.

According to the ENQA, the basic principles for good benchmarking are:

- benchmarking includes an element of comparison such as a set of common criteria against which the program/institution is assessed;

- benchmarking implies a strong element of learning and a commitment to improve one's own practices;

- benchmarking is an ongoing and time-consuming process that continues even after the specific project has been brought to a conclusion and which aims to contribute to continuous improvements;

- in order to obtain the learning element in the benchmarking process, it's important to establish internal ownership of the process among the various parties involved; and

- if ranking is a part of the benchmarking procedures, the ranking information should be on disposition to all subjects as objectively as possible. The principle of "good ranking" involves:

- the ranking criteria known prior the self-evaluation is starting;

- precisely defined multidimensional standards applied in a way of making institutional comparisons more unified; and

- defined possibilities/necessities of using qualitative data in order to make comparisons culturally acceptable.

In terms of ranking, possible "cultural" disadvantage would be that the ranking's procedure could constrain self-critical evaluation and - in the same sense - prevent the formation of a learning culture inside of institution/organization.

\section{Quality Indicators and "Creative" Benchmarking}

With creative benchmarking the university or the university's department could perform comparative assessment with foreign partner or even other higher education institution. The partners gain valuable insight into their own teaching and studying practices. Indicators that might be considered for the purpose of describing the activity and performance of universities in teaching and research are selected by the following main criteria groups (Tavenas, 2004):

- the availability of the necessary basic data;

- the extent to which the forms of organization or activities described by these data are readily comparable;

- the relevance of the information for potential users/educational consumers;

- the aims pursued by universities in regards to performance reporting.

In order to follow previous main criteria, their applicability to curriculum comparison and to cooperation-building could easily being evaluated. As case studies showed already, in an ideal 
situation it may lead to the establishment of study programs that adapt the best practices of both partners (see: Currie\&Krbec\&Matulich, 2004). According to results of the international and intercultural mission's exchange, the authors highlited the criteria concerning to:

The fundamental criterion is how well the program fulfills the educational mission of that constituent. At the student level the mission is to allow the student to develop skills in critical thinking, to think across disciplinary and national boundaries, and to apply principles learned in the classroom. The educational mission for faculty is to broaden the classroom environment beyond lecturing, to enhance teaching skills and to learn to teach in English. The institution's educational mission is to broaden and modernize its curriculum, to develop a degree of autonomy as allowed by the ministry, and to build a quality graduate program by attracting foreign and domestic students. The government through the Ministry of Science, Education and Sport is modernizing the higher education system in Croatia in an effort to improve the quality of education. It also wants to encourage alternative pedagogical approaches, disseminate the use of technology and empower local institutions to be creative within the general educational policy of the government (Curie, Krbec, \& Matulich, 2004).

Although criteria formulation depends on the aim of the creative benchmarking, developing the methodology for international evaluation with a comparative perspective represent a significant challenge. Even the draft set of criteria have been driven by broadness, uniformity, reference, topicality etc., the evaluation should illustrate the commonalities and differences carrying out from a methodology adopted by both institutions.

Based on the similar experiences, the partners should select people for the benchmarking teams. The most important task for the teams is to build assessment matrices, which are composed of questions needed for the bilateral comparison work. The matrices represent qualitative questionnaires on the organization of teaching, curriculum, teaching methods and quality assessment (if exist). They can also represent a different cultural approach to subjects of assessment.

\section{Recommendations}

Despite the majority of positive recommendations for using benchmarking and successful examples of its current use, there are critics of its applicability to higher education. The stated objections include the belief that benchmarking is merely a strategy for marginally improving existing processes, that it is applicable only to administrative processes (or only to teaching practices), is a euphemism for copying, is lacking innovation, or that it can expose institutional weaknesses as described by Alstete (1995).

But, raising or shaping the "culture of evidence" should be seen as a long-term activity for establishing the empirical basis for the quality culture of a higher education institution. "As it relates to institutional quality culture, the culture of evidence is that habit required in a HE institution and based on clear ethical values, principles, and rules, which consists of the self-evaluation of its learning outcome, engaging the teaching staff and the academic administration in a thoughtful, regular collection, selection, and use of relevant institutional performance indicators" (UNESCOCEPES, 2004, p. 33-34).

The final goal of the present reform processes in the countries - usually called as «new comers» (to the community of the European Union member states) - is an establishment of the best practice as a superior method, which is in the same shape an innovative process for every national HE system. Because the best practice doesn't necessarily represent an absolute pattern, the 
application of it is continuous improvement activity toward the achievement of established quality standards of each institution.

In the context of the growing diversity and expected level of quality of higher education, the translation of academic quality into standards/indicators has become much more complex than it was expected previously. The list of standards is composed by reality-based components and potentiality-focused ones, and it should also include a definition of the responsibilities of the bodies and institutions involved. According to the Act on Scientific Activity and Higher Education (accepted in July 2003, with a number amendments added in July and November 2004), the Ministry of Science, Education and Sport (MSES) Republic of Croatia, the National Council for Higher Education, the Agency for Science and Higher Education, the Croatian Rectors' Conference, and students' associations are the bodies responsible for the process of accreditation and quality assurance procedures for HE institutions in Croatia.

The question that rises from above classifications and methodological framework should be: how to implement effective assessment process that areas needing a mere adjustment can be identified and addressed? Experts are agreed that administrative practices must be in place to accommodate the continuous evaluation of an organization's structure and procedures applied in it. Learning what needs to be changed is one of the most challenging aspects of making institutional improvements.

\section{Conclusion}

Benchmarking is more than just collecting data. It involves adapting a new approach of continually questioning how processes are performed, seeking out best practices, and implementing new models of operation. In this sense, benchmarking is a tool of innovative (administrative) practice that leads to the organization's innovation.

In the processes of the quality assurance's shaping, and with the main purpose of a final increasing of the public effectiveness, every public sector institution (and the institution belonging to the higher education sector) should define starting methodological points of the SMART strategy for managing the quality of "educational services" $(\mathrm{S}=$ specific, $\mathrm{M}=$ measurable, $\mathrm{A}=$ achievable, $\mathrm{R}=$ relevant i $\mathrm{T}=$ timed, in: Flynn, 2002, p. 215).

\section{References}

Alstete, J.W. (1995). Benchmarking in higher education: Adapting practices to improve quality. 1995 Report No. 5, ASHE-ERIC Higher Education Reports. Washington, DC: The George Washington University. Retrieved May 20, 2005 from http://www.ed.gov/databases/ERIC_Digests/ed402800.html

Bender, B.E. (2002). Benchmarking as an administrative tool for institutional leaders. New Directions for Higher Education, 118 (Summer 2002), 113-120.

Brennan, J. (1999). Evaluation of higher education in Europe. In M. Henkel \& B. Little (Eds.), Changing relationships between higher education and state (p. 219-235). London: Jessica Kingsley Publishers.

Bush, T. (1995). Theories of educational management. London: Paul Chapman.

Currie, D. M., Krbec, D. \& Higgins, J. (2005). Creating a quality assurance system for Croatian higher education. Higher Education in Europe - Thematic issue "The Bologna Process: Retrospect and Prospects”, $X X X(1), 53-66$.

Currie, D. M., Krbec, D. \& Matulich, S. (2004). The use of a global business practicum in promoting international competence. In I. Alon \& J. R. McIntyre (Eds.), Business education and emerging market economies: Perspectives and best practices (p. 251-266). Boston: Kluwer Academic Publishers. 
The European higher education area - Achieving the goals. (2005). Communiqué of the Conference of European Ministers Responsible for Higher Education. Bergen, 19-20 May 2005.

Flynn, N. (2002). Public sector management (4th ed.). Harlow: Pearson Education Ltd.

Hämäläinen, K., Hämäläinen, K., Dǿrge Jessen, A., Kaartinen-Koutaniemi, M.\& Kristoffersen, D. (2003). Benchmarking in the improvement of higher education. ENQA Workshop Reports 2. Helsinki: ENQA.

Hämäläinen, K., Pehu-Voima, S. \& Valhén, S. (2001). Institutional evaluations in Europe. ENQA Workshop Reports 1. Helsinki: ENQA.

Krbec, D. (2005). Innovations and cultural encounters. Challenges on benchmarking in higher education. Wokrshop: Innovation and Social Development in the Knowledge-Based Economy/Society. IUC-InterUniversity Centre, Dubrovnik, May 27-29, 2005.

Krbec, D. (2003). Institutional framework of educational innovations. In proceedings of Enterprise in Transition. Split: Faculty of Economics, p. 209-210 (CD-ROM: p. 931-942).

McNay, I. (1995). From the collegial academy to corporate enterprise: The changing cultures of universities. In T. Schuller (Ed.). The changing university? (p. 105-115). Buckingham, UK: Society for Research In Higher Education.

Meyer, J. W. \& Rowan, B. (orig. 1977). Institutionalized organizations: Formal structure as myth and ceremony. In W. W. Powel. \& P. DiMaggio (Eds.), (1991). The New Institutionalism in Organizational Analysis. Chicago: University of Chicago Press.

Morris, D. R. (1996). Institutionalization and the reform process: A system dynamics perspective. Educational Policy, 10(4), 427-447.

Neave, G. (1998). The evaluative state reconsidered. European Journal of Education, 33(3), 265-285.

Nyborg, P. (2002). A decade of transition in European higher education. Norwegian Council for Higher Education. Working Paper. Tirana Seminar November 7-8, 2002

Pusser, B. (2003). Beyond Baldridge: Extending the political model of higher education organization and governance. Educational Policy, 17(1), 121-140.

Tavenas, F. (2004). Quality assurance: A reference system of indicators and evaluation procedures. Brussels: EUA - European University Association.

UNESCO-CEPES. (2004). Quality assurance and accreditation: A glossary of basic terms and definitions. Prepared by: Vlãscenau, L., Grünberg, L. \& Pârlea, D. UNESCO-CEPES Papers on Higher Education. Bucharest: UNESCO-CEPES.

\section{Biography}

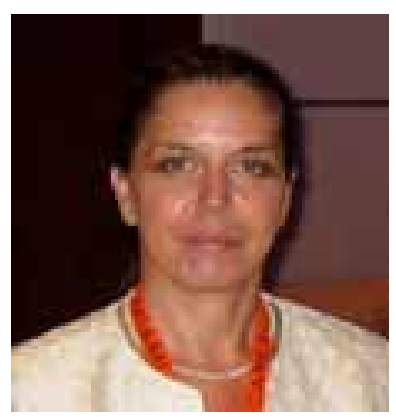

Denisa Krbec is Professor of Sociology and Head of the Department of Tourism at the Faculty of Economics and Tourism Pula, University of Rijeka, Croatia. She was the conference director of the 2003 International Conference «Globalization and Entrepreneurship: Challenges, Fears, and Opportunities». Her research interests lie in economic sociology and sociological analyses of higher education reforms. 